\title{
Proceeding
}

Supplementary Issue: Autumn Conferences of Sports Science. Costa Blanca Sports Science Events, 2-3 November 2018.

Alicante, Spain

\section{Study of human muscle aging through fiber mechanical, molecular myofibrillar and proteomics analysis}

\author{
ALESSANDRA NART ${ }^{1}$, STEFANO SCARPA ${ }^{2}$ \\ 1 University of Padua, Italy \\ 2University "Giustino Fortunato of Benevento", Italy
}

\begin{abstract}
Aging significantly influences the proteomic structure of the cell as well as the nervous component. The innovative aim of this study is to analyse the modifications of muscle tissue in aging both through a qualitative, quantitative and proteomics approaches of the whole muscle and of the single fiber compared between young and old were studied. A sample of muscle tissue from the vastus lateral was taken with an open technique by 16 volunteers, 8 young donors and 8 elderly. In the aging process there is a negative modification of all the components of the contractile system and of the systems connected to the translation of the force and to the stabilization of myofibers. Key words: Muscle aging; Fiber mechanical; Molecular myofibrillar; Proteomics.
\end{abstract}

\section{Cite this article as:}

Nart, A., \& Scarpa, S. (2019). Study of human muscle aging through fiber mechanical, molecular myofibrillar and proteomics analysis. Journal of Human Sport and Exercise, 14(1proc), S126-S131. doi:https://doi.org/10.14198/ihse.2019.14.Proc1.15

Corresponding author. University "Giustino Fortunato of Benevento", Italy.

E-mail: stefano.scarpa@unipd.it

Supplementary Issue: Autumn Conferences of Sports Science. Costa Blanca Sports Science Events, 2-3 November 2018. Alicante, Spain.

JOURNAL OF HUMAN SPORT \& EXERCISE ISSN 1988-5202

(c) Faculty of Education. University of Alicante.

doi:10.14198/jhse.2019.14.Proc1.15 


\section{INTRODUCTION}

Skeletal muscle tissue is a complex organ and plays a very important role in the movement, the functioning of the metabolism and thermoregulation. Its relevance to health, however, is not always taken in consideration. The muscle is made by a set of syncytial fusiform cells, called the myocytes; the myocytes contain the sarcomeres, the real protein contractile apparatus, consisting of so-called myofibrillar proteins of the cytoskeleton. The sarcomere is composed of filaments of actin and myosin which flow actively within each other to generate the force of muscle contraction. The thin filaments of actin and the thick filaments of myosin are kept parallel and ordered both at rest and during contraction phase, respectively by the $Z$ line and the $\mathrm{M}$ band, two protein structures that are placed at fixed distances, determining the banded aspect of the muscle fiber. The sarcomeres are kept in order both during the rest phase and during contraction phase by the costameri and the intermediate filaments, which are distributed uniformly all along the muscle fiber $(1,2,3)$.

Skeletal muscle is classified based on its contraction speed, determined by the preponderance of a given isoform of myosin. The myocyte can thus be defined as slow or fast, and the phenotype can change over time, as happens with aging. In fact, muscle tissue undergoes an important remodeling with aging: changes its contractile phenotype, with a shift from fast to slow. As a consequence, there is a relative decrease of fast fibers, with an increase in slow fibers, which in time become predominant. The aging process has an important influence both on the proteomic structure of the cell, as well as on its nervous component. This produces a pathophysiological framework where the slowdown of protein synthesis is accompanied by axonal atrophy essential for an efficient muscle contraction. This set of factors finally leads to a loss in the volume of the muscle fibers, resulting in less strength and performance (4).

\section{Purpose of the study}

The aim of this study is to analyze the change in the aging muscle tissue. The novelty of that research consists in an equal and equal and parallel analysis of the differences from both: a qualitative (force), a quantitative (section) and a molecular (proteomic) point of view of individual muscle fibers. As for the entire muscle is concerned, only the qualitative differences between young and elderly subjects will be taken into account in this study. A further aim of the study is to find the link between the decrease in strength and the proteomic changes in the muscle fibers $(5,6)$.

The study is very original and relevant as we have not detected other studies that use the same procedures to achieve the objectives set. Moreover, the potential results would have important repercussions for the population and in particular for a 'successful aging' of the elderly.

\section{MATERIALS AND METHODS}

\section{Population of the study}

16 male volunteers: 8 young donors (22-27 years) and 8 elderly elderly donors (66-75 years) participated to the study. They were all in a good state of health.

\section{Procedure}

A sample of muscle tissue from the vastus lateralis of the quadriceps was analyzed for both categories. All donors conduct a moderate physical activity. We used the Global Physical Activity Questionnaire (GPAQ) proposed by World Health Organization (7) - in order to assess the intensity of daily physical activity. The tissue sample was dissected to obtain individual fibers. Those fibers have been analyzed in two different ways: proteomic analysis at the Max Planck Institute of Monaco of Bavaria, and biomechanical analysis at 
the Physiology department of the University of Padua. As for the in vivo analysis, the maximal isometric strength voluntary tests were performed at the Department of Kinesiology of the University of Verona.

\section{Statistical analysis}

All data were processed using the SPSS 22.0 program. Age and anthropometric characteristics are expressed as mean \pm standard deviation (SD). Comparisons and differences between groups were analyzed by Analysis of variance (one-way ANOVA). The alpha-error probability was set at $p<0.05$ (2-sided). The relatioships bettween variable was carried out wit Pearson correlations $r$. Effect size was estimate by Cohen d.

\section{RESULTS}

The anthropometric analyzes of all the subjects are reported in below in Table 1.

Table 1. Anthropometric analyzes of all the subjects

\begin{tabular}{|c|c|c|c|c|}
\hline \multirow{2}{*}{ Participants } & Young donors & \multicolumn{2}{|c|}{ Elderly donors } & \multirow[b]{2}{*}{ Effect Sizes } \\
\hline & & & & \\
\hline Varibles & Means (SD) & Means (SD) & p-values & Cohen's d \\
\hline Age (years) & $23.60(1.35)$ & $70.25(1.33)$ & $<.0001^{*}$ & 35.07 \\
\hline Weight (kg) & $77.50(1.11)$ & 71. (1.23) & NS & l \\
\hline Height (cm) & $181(4.34)$ & $168(3.82)$ & $.033^{*}$ & 3.17 \\
\hline$B M I$ & $24.49(1.11)$ & $24.40(1.95)$ & NS & l \\
\hline Waist circumference (cm) & $84.6(1.7)$ & $83.5(1.94)$ & NS & I \\
\hline Hip circumference (cm) & $98.01(1,11)$ & $97.55(.93)$ & NS & I \\
\hline WAIST-TO-HIP O RATIO & $.86(.008)$ & $.87(.005)$ & NS & l \\
\hline Comorbidity & 0.00 & 0.00 & NS & l \\
\hline
\end{tabular}

The overall section of the fibers in the elderly subjects is $20 \%$ lower than the young subjects $(p=.0004)$, the fibers taken into consideration are the IIA, I, IIA IIX, IIA IIX and IIX, the latter are present only in the young people.

Regarding the cross section of the Slow or ST and Fast or FT fibers: the elderly subjects have a section of the fibers containing the myosin $\mathrm{MHCl}$ isoform $(p<.05)$ and $\mathrm{MHCll}(p<.01)$ of $20 \%$ lower than the young subjects. The decrease in the section is attributable to a constant decline of both pure myosin types. Elderly subjects show a significant decrease in the maximum isometric strength (F0) of $45 \%$ ( $<.001)$, taking all fibers independently of the isoform into consideration.

Both F0 of type 1 fibers ( $p=.007$ ) and type 2 fibers ( $p=.002$ ) undergoes a significant decrease. However, no significant differences were found between the 2 morphotypes as the F0 decrease in Type I fibers and Type II fibers is the same (i.e. $30 \%$ ).

The specific strength is lower than the F0. The study of proteomics through the study of costumers and of myosin isoforms could highlight the reasons for this deficit. 
Compared to F0, the specific force relative to all the fibers (P0) undergoes a significant drop of $15 \%$ with a $p$ value $=.001$.

The difference between the specific strength related exclusively to type I fibers and type II fibers was not significant ( $p=.138$ for type I, $p=.125$ for type II). The quantity of type I fibers is higher in the elderly. However, the elderly also presents a greater number of fibers of the IIA type. The IIAIIX mixed isoform is visibly greater in young people. No IIX myosin isoform has been found.

Young people have more type II fibers than older people. Both the F0 and the strength of the quadriceps obtained through resting electrical stimulation (QtW Pot) is significantly higher in young subjects than in elderly subjects ( $p=.02$ and $p=.006$, respectively) which show a decrease in the maximum voluntary and stimulated contraction $(51 \%)$.

Both the percentage of muscle recruitment $(p<.05)$ and the rate of force development $(p<.05)$ are significantly higher in the young MFV\% y $=94(+-3)$ compared to the elderly MFV\% $\mathrm{O}=86(+-6)$.

The percentage of recruitment (\% MFV) of the motor units is greater in young subjects than in elderly subjects $(p<.05)$ and the overall fiber section in elderly subjects decreases by 20\% compared to young subjects $(p=$ .0004), the fibers taken into consideration are the IIA, I, IIA IIX, IIA IIX and IIX (the latter are present only in young people).

The values for the rate of strength development are also significantly higher in the young MRFy $=1069(+-$ 331) compared to the elderly MRFo $=493(+-315)$. The rate of development was obtained by dividing the mean value of the strength expressed during the electrical stimulation at rest with the time taken to reach $90 \%$ of the peak of expectable strength under stimulation.

With regard to the speed of the degeneration of resistance in the elderly, their decrease is related to the changes that the aging process implements on the muscle fibers: in the aging process there is a decrease in both the diameter and the length of the muscle fibers (10/20\%) with a consequent decrease in the maximum speed of contraction and in the development of the strength.

Regarding the relaxation rate, there is an insufficient significance difference between groups that can be traced back to the scarce sample recruited.

\section{DISCUSSION}

Concerning the in vitro tests, the maximum isometric strength, the specific strength and the single fiber section is significantly lower in the elderly which has a modest decline in type II fibers. In the in vivo strength tests, both the maximum voluntary contraction and the percentage of muscle recruitment undergo a significant decrease in the elderly subjects. In proteomics test there is a significant decrease of both the sarcoplasmic reticulum (SR) proteins and myofibrillar proteins $(8,9,10)$.

The morphological findings reveal that in the elderly individuals there is a $20 \%$ decrease in the cross sectional area (CSA) of both type II and type I fibers. In that population, there is also a proportional increase in type I fibers compared to type II fibers: this is due to the increased susceptibility of type II fibers to oxidative stress. Thus, in elderly people there is a shift that sees type I fibers prevail over type II fibers. The fiber pool in young 
subjects is $33 \%$ for type I fibers and $67 \%$ for type II fibers. While in elderly subjects it is $44 \%$ for type I fibers and $56 \%$ for type II fibers $(1,2,3)$.

The results on the drop in strength of each individual fiber show that in the elderly there is a decrease of $30 \%$ of the maximum isometric strength of the muscle fibers. That decrease is mainly due to the reduction of the CSA, which also leads to the reduction of the cross bridges indispensable for the generation of power. However, also the specific strength undergoes a significant decrease (15\%), underlining how the modifications of the myosin chains, given by the increase of the oxidative stress present in the elderly, can go to negatively modify the link between the actins and the myosin heads $(1,2,3,11,12)$.

The results on in vivo force decline highlight the fact that the results obtained in in vivo dynamometric tests show that both the force of the maximum voluntary contraction and the force developed as a result of the electric stimulation at rest (QtW Pot) are significantly higher in young subjects than in elderly subjects who have a decrease of the maximum voluntary and stimulated contraction of $51 \%$. It is considered that the decrease in strength is very little dependent on the decrease in muscle trophism and it should instead be considered as a factor dependent on the degeneration of the central nervous system. In the elderly there is a decrease in the speed of development of the strength given by the lack of inter-intramuscular coordination due to the altered $\mathrm{Ca}+$ reuptake by the sarcoplasmic reticulum, increase of synaptic terminals by motoneurone, decrease of type II fibers (1-5, 9-13).

Finally, the results on proteomics show that sarcoplasmic reticulum (SR) proteins undergo a significant decline in the elderly and they are primarily those responsible for calcium reuptake from myofibrillar sarcoplasm. Myomasin 1 and Myomasin 2 fall by 30\% and 20\% respectively. Myomasin deficiency could justify both the representative muscular fragility of the elderly subjects and their lesser strength compared to the control subjects (1-6, 9-12).

\section{CONCLUSION}

In the aging process all the components of the contractile system are modified. The damage is not only about to the diameter or length of the individual muscle fiber, but also going to affect the re-uptake of calcium from the cytosol to the sarcoplasmic reticulum (SR Ca ${ }^{2+} \mathrm{ATP}$-ase and sarcolumenina), the translation of force and the stabilization of myofibers -proteins of $\mathrm{M}$ line- $(14,15)$.

\section{CONTRIBUTION OF EACH AUTHOR}

ALESSANDRA NART, PH.D is the first author of the research. He is the guide, the supervisor of the project and the scientific coordinator of the research.

STEFANO SCARPA, PH.D is the second author of the research. He is the creator of the project. From a practical point of view he collected all data. He contributed to developed, in particular, those parts of the research: study design, data collection and analysis.

\section{REFERENCES}

Narici, M. V., Maganaris, C. N., Reeves, N. D., Capodaglio, P. Effect of aging on human muscle architecture. J. Appl. Physiol. 2003; 95: 2229-2234. https://doi.org/10.1152/japplphysiol.00433.2003 
Delmonico, M. J., Harris, T. B., Visser, M., Park, S. W., Conroy, M. B., Velasquez-Mieyer, P., Boudreau, R., Manini, T. M., Nevitt, M., Newman, A. B., Goodpaster, B. H. Longitudinal study of muscle strength, quality, and adipose tissue infiltration. Am J Clin Nutr. 2009; 90: 1579-85. https://doi.org/10.3945/ajcn.2009.28047

Goodpaster, B. H., Park, S. W., Harris, T. B., Kritchevsky, S. B., Nevitt, M., Schwartz, A. V., Simonsick, E. M., Tylavsky, F. A., Visser, M., Newman, A. B. The loss of skeletal muscle strength, mass, and quality in older adults: the health, aging and body composition study. J Gerontol A Biol Sci Med Sci. 2006; 61: 1059- 64. https://doi.org/10.1093/gerona/61.10.1059

D'Antona, G., Pellegrino, M. A., Adami, R., Rossi, R., Carlizzi, C. N., Canepari, M., Saltin, B., Bottinelli, $R$. The effect of ageing and immobilization on structure and function of human skeletal muscle fibres. J. Physiol. Lond. . 2003; 552: 499-511. https://doi.org/10.1113/jphysiol.2003.046276

Andersen, J. L. Muscle fibre type adaptation in the elderly human muscle. Scand. J. Med. Sci. Sports. 2003; 13: 40-47. https://doi.org/10.1034/j.1600-0838.2003.00299.x

Siwya, J., Vlahoub, A., Zimmerlic, L.U., Zürbig, P., Schiffera, E. Clinical proteomics: Current techniques and potential applications in the elderly. Maturitas. 2011: 68(3): 233-244. https://doi.org/10.1016/i.maturitas.2010.11.001

Wanner, M., Hartmann, C., Pestoni, G.; Martin, B. W., Siegrist, M., Martin-Diener, E. Validation of the Global Physical Activity Questionnaire for self-administration in a European context. BMJ Open Sport \& Exercise Medicine. 2017; 3(1): 1-10. https://doi.org/10.1136/bmisem-2016-000206

Kadi, F., Charifi, N., Denis, C., Lexell, J. Satellite cells and myonuclei in young and elderly women and men. Muscle Nerve. 2004; 29: 120-127. https://doi.org/10.1002/mus.10510

Andersen J. L. , Klitgaard H., Saltin B. Myosin heavy chain isoforms in single fibres from $\mathrm{m}$. vastus lateralis of sprinters: influence of training. Acta Physiol Scand . 1994; 151: 135-142. https://doi.org/10.1111/j.1748-1716.1994.tb09730.x

Pedersen, M., Bruunsgaard, H., Weis, N., Hendel, H. W., Andreassen, B. U., Eldrup, E., Dela, F., Pedersen, B. K. Circulating levels of TNF-alpha and IL-6-relation to truncal fat mass and muscle mass in healthy elderly individuals and in patients with type-2 diabetes. Mech. Ageing Dev. . 2003; 124: 495-502. https://doi.org/10.1016/S0047-6374(03)00027-7

De Benedetti, F., Alonzi, T., Moretta, A., Lazzaro, D., Costa, P., Poli, V., Martini, A., Ciliberto, G., Fattori, E. Interleukin 6 causes growth impairment in transgenic mice through a decrease in insulin- like growth factor-I. A model for stunted growth in children with chronic inflammation. J. Clin. Invest. 1997; 99: 643-650. https://doi.org/10.1172/JCl119207

Larsson, L., Li, X., Frontera, W. R. Effects Of aging on shortening velocity and myosin isoform composition in single human skeletal muscle cells. Am. J. Physiol. 1997; 272: 638-649. https://doi.org/10.1152/ajpcell.1997.272.2.C638

Pette D., Staron R.S. Molecular basis of the Phenotypic characteristics of mammalian muscle fibres. Ciba Found Synp. 1988; 138: 22-34.

Gullich, S. Struktur der Kraftfähigkeiten und ihrer Trainingsmethoden. Deutsche Zeitschrift für Sportmedizin. 1999; 50: 223-234.

Wie, L., Gregorich, Z. R., Lin, Cai, W., Jin, Y., McKiernan, S. H., Mcllwain, S., Aiken, J. M., Moss, R. L., Diffee, G. M., Ge, Y. Novel Sarcopenia-related Alterations in Sarcomeric Protein Post-translational Modifications (PTMs) in Skeletal Muscles Identified by Top-down Proteomics. Mol Cell Proteomics. 2018; 17(1): 134-145. https://doi.org/10.1074/mcp.RA117.000124

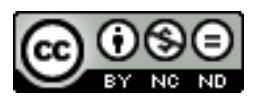

This work is licensed under a Attribution-NonCommercial-NoDerivatives 4.0 International (CC BY-NC-ND 4.0). 